Arif, M. and Jones, F. and Barifcani, A. and Iglauer, S. 2017. Influence of surface chemistry on interfacial properties of low to high rank coal seams. Fuel. 194: pp. 211-221.

\title{
Influence of surface chemistry on interfacial properties of low to high rank coal seams
}

${ }^{1}$ Curtin University, Department of Petroleum Engineering, 26 Dick Perry Avenue, 6151 Kensington, Western Australia; phone: +61 892667703

${ }^{2}$ Department of Applied Chemistry, Kent Street, Curtin University, Bentley, WA, 6102

${ }^{*}$ Corresponding author

Phone: +61 892667703

Fax: +61 892667063

Email: muhammad.arif@curtin.edu.au

\section{Abstract}

Wettability of $\mathrm{CO}_{2} /$ water/coal systems is a fundamental petro-physical parameter, which governs the fluid flow and distribution in coal seams and thus directly affects $\mathrm{CO}_{2}$-storage and methane recovery from unmineable coal seams. The recognition of wettability of coal/ $\mathrm{CO}_{2} /$ brine systems help to de-risk $\mathrm{CO}_{2}$-storage and enhanced methane recovery projects in coal seams. To understand the factors influencing the wetting characteristics of coals, a detailed examination and characterization of coal surface chemistry is essential and literature data in this context is missing. We thus measured zeta potentials as a function of temperature (298 K-343 K), brine salinity ( $0 \mathrm{wt} \% \mathrm{NaCl}-5 \mathrm{wt} \% \mathrm{NaCl})$ and salt type $\left(\mathrm{NaCl}, \mathrm{CaCl}_{2}\right.$ and $\mathrm{MgCl}_{2}$ ) for coals of low, medium and high ranks. Further, we measured water advancing and receding contact angles as a function of temperature and salinity for the same experimental matrix in order to associate wettability changes to the surface charge at the coal/brine interface.

Moreover, coal surfaces were investigated by Fourier transformed infrared (FTIR) spectroscopy and the surface functional groups responsible for a particular wetting behaviour 
were identified. We found that zeta potential increased with temperature, salinity and cation valency. Both advancing and receding contact angles decreased with temperature, and increased with salinity and cation valency irrespective of the coal rank. Finally the XRD measurements and infrared spectra revealed that the presence of polar surface functional groups (e.g. Si-OH and carboxylic acid groups) which is responsible for the hydrophilic behaviour of low rank coals and the absence of these groups in high rank coal is responsible for their hydrophobic behaviour even at lower pressure. The high rank coal seams at high pressure are better for $\mathrm{CO}_{2}$ storage and methane recovery.

\section{Introduction}

The injection of $\mathrm{CO}_{2}$ in depleted oil and gas reservoirs or deep saline aquifers is capable of trapping tremendous amounts of $\mathrm{CO}_{2}$ and thus reduce anthropogenic $\mathrm{CO}_{2}$ emissions [1-3]. Certain trapping mechanisms render $\mathrm{CO}_{2}$ immobile in the porous medium, and these are structural trapping [4-7], residual or capillary trapping [8,9], dissolution or solubility trapping [10] and mineral trapping [11]. Coal seams, too, offer enormous potential for $\mathrm{CO}_{2}$ storage and enhanced methane recovery by means of preferential adsorption of $\mathrm{CO}_{2}$ [12,13]. Adsorption is the major $\mathrm{CO}_{2}$ trapping mechanism in unminable coal seams and the wettability of the specific $\mathrm{CO}_{2} /$ brine/coal system plays a significant role in this context [12,14]. Typically, the adsorption capacity of $\mathrm{CO}_{2}$ is higher than that of methane, consequently, $\mathrm{CO}_{2}$ displaces methane toward the production well and itself gets sorbed within the micropores of the coal seam and remains trapped [12]. Moreover, Arif et al. [12] pointed out that higher $\mathrm{CO}_{2}$-wettability would lead to higher $\mathrm{CO}_{2}$-adsorption and thus higher storage [12].

Although coal wettability has been characterized as a function of pressure, temperature, salinity and coal rank $[12,15]$, the factors responsible for a particular wetting behaviour are so far unclear. Specifically, the knowledge and characterization of coal surface chemistry is essential to understand the factors that influence its wettability $[16,17]$. In this context, zeta potential is used to probe the double layer at the surface of the coal. The nature of the double layer affects the repulsion/attraction of system's components, and depends upon the physicochemical properties of all components in the overall system [18]. Thus, what occurs at the brine/mineral or brine/rock interface (at a particular temperature and brine salinity) is strongly affected by the electrical double layer and studies have shown that this double layer is closely related to wettability [19-21]. 
We thus examined the electrochemical behaviour of coal by measuring zeta potentials as a function of temperature (298 K-343 K), salinity (0 wt\% NaCl-5 wt\% $\mathrm{NaCl})$, salt type ( $\mathrm{NaCl}$, $\mathrm{CaCl}_{2}$ and $\mathrm{MgCl}_{2}$ ) and coal rank (low, medium and high rank) to allow surface characterization for broad range of conditions. In addition, following the same experimental matrix, we measured advancing and receding contact angles for air/coal/brine systems (at ambient pressure). The associated trends were analysed systematically and relationships were developed between zeta potential and wettability. We found that the zeta potential increased with increasing rank and increasing salinity and contact angles also increased with increasing rank and salinity, implying a positive correlation between zeta potential and wettability. However, with increasing temperature zeta potential increased but contact angle decreased, implying that correlation with respect to temperature is inconsistent. Moreover, the zeta potential results were also compared to our published contact angle data at high pressure, and we hypothesized that zeta potential at high pressure may follow similar trends as those at ambient pressure.

Further, in order to evaluate the impact of coal rank on wettability of the coal/ $/ \mathrm{CO}_{2} /$ brine systems, we conducted Fourier transformed infrared spectroscopy (FTIR) measurements on the three coal samples (low, medium and high rank) and thoroughly characterized the surface functional groups. The results demonstrated that the abundance of $\mathrm{OH}$ and carboxylic acid groups on the low rank coal is responsible for the hydrophilic nature of lignite and the lack of these groups explains the hydrophobic nature of high rank coal (semi-anthracite).

\section{Experimental Methodology}

\subsection{Fluid/sample preparation}

Three coal samples [high rank (semi anthracite; from Hazelton, Pennsylvania, USA), medium rank (medium volatile bituminous; from Morgantown, West Virginia, USA), and low rank (lignite; from North Dakota, USA; Table 1)] were used in this research. The samples were cut to cuboid shape $(\sim 1 \mathrm{~cm} \times 1 \mathrm{~cm} \times 0.5 \mathrm{~cm})$ or crushed into fine powder (particle size $\sim 30$ microns) using milling equipment (Labtechnics Adelaide, Model TP-4/5, and Oscillation: 50Hz). The powdered samples were then placed in an oven at $90^{\circ} \mathrm{C}$ for 12 hours until the weight became constant. 
$92 \mathrm{Coal} / \mathrm{brine}$ composite samples for all coal ranks were prepared by adding $2 \mathrm{wt} \%$ coal powder to aqueous salt solutions composed of DI water $(0 \mathrm{M}), 1 \mathrm{wt} \% \mathrm{NaCl}(0.17 \mathrm{M}), 5 \mathrm{wt} \% \mathrm{NaCl}$ (0.855M), $1 \mathrm{wt} \% \mathrm{CaCl}_{2}(0.27 \mathrm{M})$, and $1 \mathrm{wt} \% \mathrm{MgCl}_{2}(0.305 \mathrm{M})$. Note: the numbers in brackets represent the equivalent ionic strength of electrolyte which is typically preferred while comparing different types of salt of same strength. In this paper, we mainly used wt\% to express salinity, however, for salts comparison we used ionic strength (Section 3.3). Moreover, the alternative common units to express salinity are 'mg/L' and 'ppm'.

Materials used were de-ionized water (Conductivity: $0.02 \mathrm{mS} / \mathrm{cm}$ ) and brine comprising of $\mathrm{NaCl}, \mathrm{CaCl}_{2}$ and $\mathrm{MgCl}_{2}$ (Salts Source: Scharlab s.1., Spain, Purity: $\geq 0.995$ mass\%). The solutions were covered with parafilm and stirred for 5 hours using a magnetic stirrer at $40{ }^{\circ} \mathrm{C}$ to ensure homogenous dispersion of the solid powder within the base liquid. The dispersions were then used for the zeta potential measurements. For contact angle measurements, the cuboid samples (low, medium and high rank coal) were selected and for spectroscopic measurements samples were used in powdered form.

\subsection{Zeta potential measurements}

Zeta potential was measured on a Zetasizer Nano ZS (Malvern instrument). The coal dispersion was placed in a folded capillary cell and sealed at the top. The zeta potential was measured for coal/DI-water for high, medium and low rank coals at $298 \mathrm{~K}, 308 \mathrm{~K}, 323 \mathrm{~K}$ and $343 \mathrm{~K}$ to investigate the effect of temperature on zeta potential. Moreover, the effect of salinity and cation type was analysed for coal dispersed in 1 wt $\% \mathrm{NaCl}, 5$ wt $\% \mathrm{NaCl}, 1 \mathrm{wt} \% \mathrm{CaCl}_{2}$ and 1 $\mathrm{wt} \% \mathrm{MgCl}_{2}$ brine. The measurements were repeated three times and the standard deviation of zeta potential measurements was $3 \mathrm{mV}$ at $298 \mathrm{~K}, \sim 2.5 \mathrm{mV}$ at $308 \mathrm{~K}$ and $\sim 1.5 \mathrm{mV}$ at $323 \mathrm{~K}$ and $343 \mathrm{~K}$. Moreover, for higher salinities ( $5 \mathrm{wt} \% \mathrm{NaCl}$ ), standard deviation was also high (3 mV). We used error bars to graphically represent the standard deviation in our results. We observed that the sources of error in zeta potential measurements are evaporation, time lapse between sample preparations to actual measurement, degree of homogeneity of mixing, size of coal particle and electrolyte strength. If these factors are not properly addressed the Zetasizer Nano ZS may give different quality of measurements. We here reported the best three set of measurements which we observed. 
124 The results of the proximate, ultimate and petrological analysis and the internal properties 125 (density and volume) of the coal samples are listed in Table 1. Note that coal samples of 126 different rank differ mainly in volatile matter, moisture, fixed carbon and vitrinite reflectance 127 [22]. Petrology was analysed in accordance with Australian Standard AS2856 and ISO7404; 128 proximate analysis was conducted using standards AS1038.3, ISO11722 and ASTM D3172129 07a, and ultimate analysis was performed using standards AS1038.6 and ISO 609.

131 Table 1. Properties of coal samples used.

\begin{tabular}{|c|c|c|c|c|}
\hline \multirow{3}{*}{$\begin{array}{l}\stackrel{\mathscr{J}}{\bar{\Xi}} \\
\text { ñ }\end{array}$} & Rank & Semi-Anthracite & $\begin{array}{l}\text { Medium-volatile } \\
\text { Bituminous }\end{array}$ & Lignite \\
\hline & Geological Location & $\begin{array}{l}\text { Hazelton, } \\
\text { Pennsylvania }\end{array}$ & $\begin{array}{l}\text { Morgantown, } \\
\text { West Virginia }\end{array}$ & North Dakota \\
\hline & Overall rank (used in this work) & High rank & Medium rank & Low rank \\
\hline \multirow{5}{*}{ 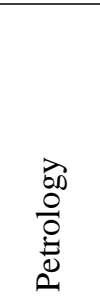 } & Vitrinite Reflectance $\left(\mathrm{R}_{0}, \%^{*}\right)$ & 3.92 & 0.82 & 0.35 \\
\hline & Vitrinite (\%) & 89.6 & 73.1 & 83 \\
\hline & Liptinite (\%) & 0 & 3.4 & 4 \\
\hline & Inertinite (\%) & 7.6 & 18.8 & 10.8 \\
\hline & Minerals (\%) & 2.8 & 4.7 & 2.1 \\
\hline \multirow{4}{*}{ 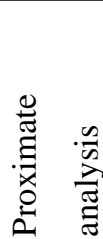 } & Moisture (air dried, \%) & 2.6 & 2 & 16.3 \\
\hline & Ash (\%) & 9.7 & 6.4 & 7.8 \\
\hline & Volatile Matter (\%) & 2.9 & 32.4 & 34.8 \\
\hline & Fixed carbon (\%) & 84.9 & 59.2 & 41.1 \\
\hline \multirow{7}{*}{ 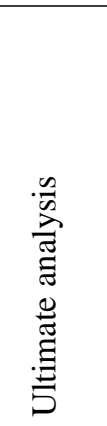 } & Ash (\%) & 9.7 & 6.4 & 7.8 \\
\hline & Carbon (\%) & 82.6 & 78.6 & 54.6 \\
\hline & Total Hydrogen (\%) & 2.35 & 5.07 & 5.27 \\
\hline & Hydrogen (\%) & 2.06 & 4.85 & 3.45 \\
\hline & Nitrogen (\%) & 1.16 & 1.54 & 0.62 \\
\hline & Total Sulphur (\%) & 0.8 & 0.99 & 0.66 \\
\hline & Oxygen by difference (\%) & 3.68 & 7.62 & 2.87 \\
\hline \multirow[b]{3}{*}{ 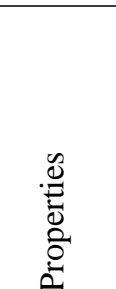 } & Bulk density (g/cc) & 1.30 & 1.28 & 1.44 \\
\hline & Dry sample volume (сc) & 16.55 & 12.77 & 4.26 \\
\hline & Dry mass (g) & 21.17 & 16.194 & 6.159 \\
\hline
\end{tabular}




\section{4. $\mathrm{pH}$ measurements}

135 The $\mathrm{pH}$ values of the solutions were measured at $298 \mathrm{~K}$ using a pH meter (model: Orion 420+ and a Thermofisher $\mathrm{pH}$ probe, accuracy: $\pm 0.005 \mathrm{pH}$ ), the results of which are tabulated in Table 2. These $\mathrm{pH}$ measurements are helpful for a) explanation of zeta potential results as a function of coal rank and brine salinity, and b) precise comparison with zeta potential literature data.

Table 2. Measured pH values of the solutions used.

\begin{tabular}{|l|c|c|l|}
\hline \multirow{2}{*}{ Electrolyte } & \multicolumn{3}{|c|}{$\mathrm{pH}$ values } \\
\cline { 2 - 4 } & Anthracite $^{*}$ & Bituminous $^{*}$ & Lignite $^{*}$ \\
\hline DI-water & 7.09 & 6.78 & 6.78 \\
\hline $1 \mathrm{wt} \% \mathrm{NaCl}$ & 8.13 & 7.37 & 6.42 \\
\hline $5 \mathrm{wt} \% \mathrm{NaCl}$ & 7.97 & 7.05 & 6.03 \\
\hline $1 \mathrm{wt} \% \mathrm{CaCl}_{2}$ & 7.57 & 6.96 & 5.48 \\
\hline $1 \mathrm{wt} \% \mathrm{MgCl}_{2}$ & 8.21 & 8 & 5.86 \\
\hline
\end{tabular}

*All solutions contained $2 \mathrm{wt} \%$ coal powder.

\subsection{Infrared spectroscopy}

144 Fourier Transformed Infrared spectroscopy was performed using a Nicolet iS50-FTIR instrument (from Thermo Scientific) at $4 \mathrm{~cm}^{-1}$ resolution. The powdered sample was placed on a diamond attenuated total reflection (ATR) crystal and pressed into contact. A total of 64 scans were added to generate the final infrared spectrum and the internally available ATR correction was applied to each spectrum with the software (which was supplied by the manufacturer with the instrument).

152 XRD analysis was carried out on the three coal samples and minerals were detected in each 153 sample (Table 3). It is evident that the coal mainly comprised of quartz and kaolinite, however, overall mineralogy of these coals is different. 
156 Table 3. Mineral identified by XRD in the three coal samples investigated.

\begin{tabular}{|l|l|c|c|c|}
\hline Mineral name & Chemical formula & $\begin{array}{l}\text { High rank coal } \\
\text { (semi-anthracite) }\end{array}$ & $\begin{array}{l}\text { Medium rank coal } \\
\text { (medium volatile } \\
\text { bituminous) }\end{array}$ & $\begin{array}{l}\text { Low rank } \\
\text { coal } \\
\text { (lignite) }\end{array}$ \\
\hline Illite & $\left({\left.\mathrm{K}, \mathrm{H}_{3} \mathrm{O}\right) \mathrm{Al}_{2} \mathrm{Si}_{3} \mathrm{AlO}_{10}(\mathrm{OH})_{2}}^{\text {Quartz }}\right.$ & 34 & 17 & - \\
\hline Kaolinite & $\mathrm{SiO}_{2}$ & 21 & 41 & 76 \\
\hline Anatase & $\mathrm{Al}_{2} \mathrm{Si}_{2} \mathrm{O}_{5}(\mathrm{OH})_{4}$ & 24 & 30 & 24 \\
\hline Montmorillonite & $\mathrm{TiO}_{2}$ & 21 & - & - \\
\hline $\begin{array}{l}\text { Illite- } \\
\text { montmorillonite }\end{array}$ & $\mathrm{HAl}_{2} \mathrm{CaO} \cdot 5 \mathrm{O}_{12} \mathrm{Si}_{4}$ & - & 6 & - \\
\hline
\end{tabular}

\subsection{Contact angle measurements}

159 Contact angles were measured using the pendant drop titled plate technique [23], the schematic of the experimental apparatus has been published previously [12]. The coal substrates were placed in the cell and temperature was set to a desired value $(298 \mathrm{~K}, 308 \mathrm{~K}, 323 \mathrm{~K}$ or $343 \mathrm{~K}$ within $\pm 1 \mathrm{~K})$. Coal surfaces were washed with acetone and then cleaned with air plasma for 2 min (within this selected time the error in contact angle measurements was minimum) and this selected time was neither too short to compromise on the surface contaminants (which need to be removed, [24]) and neither too intense to allow the removal of natural particles from the coal surfaces [12]. A few studies, however, report different coal-surface cleaning methods, e.g. the use of wet polish with abrasive papers, which were then removed by ultrasonic cleaning $[14,25]$.

Subsequently brine was pumped with a high precision syringe pump (ISCO Teledyne 500D) resulting in a droplet of de-gassed brine (vacuumed for $12 \mathrm{~h}$ ) being dispensed onto the substrate

171 (in air, at ambient pressure and the pre-set temperature) by means of a needle. At the leading edge of the droplet, just before the droplet started to move, the angle between coal surface and the brine interface was measured as the advancing contact angle $\left(\theta_{a}\right)$ whereas the receding contact angle $\left(\theta_{r}\right)$ was measured at the trailing edge of the droplet. A high performance video camera (Basler scA 640-70 fm, pixel size $=7.4$ lm; frame rate $=71 \mathrm{fps}$; Fujinon CCTV lens: HF35HA-1B; 1:1.6/35 mm) recorded the entire process, and contact angles were measured on images extracted from the movie files. The standard deviation of these measurements was $\pm 4^{\circ}$ 
based on measurements repeated thrice and is shown by error bars in the results. The measurements were done on one sample each of low, medium and high rank. The coal samples may vary in terms of composition, thus the conclusions drawn in the study may vary depending upon the composition of the coal samples under investigation. In fact, our results revealed that difference in coal rank (e.g. low, medium and high rank, which are obviously different in composition) leads to different zeta potential (at the same operating conditions) which leads to different wettability (discussed in detail in section 3.4).

\section{Results and discussion}

In order to understand the factors influencing wettability of coal seams, we examined the surface properties of coals. The results lead to a broad understanding of the factors responsible for the distinct wetting characteristics of coals as a function of coal rank, pressure, temperature and brine salinity and thus the results help to precisely understand fluid flow and distribution in coal seams. This information can be used to optimize $\mathrm{CO}_{2}$-storage and (enhanced) methane recovery projects. Below the influence of each individual parameter is discussed in detail.

\subsection{Effect of temperature on zeta potential and contact angle}

We found a clear and consistent temperature dependence trend of contact angle and zeta potential for coal/DI water systems. Zeta potentials of these systems increased with increasing temperature within the experimental error (at constant ambient pressure, Figure 1), irrespective of coal rank. Moreover, the advancing and receding water contact angles decreased with temperature for all coal ranks (Figure 2, consistent with [12]). The increase in zeta potential with increasing temperature implies a surface with more screening ions within the double layer at higher temperatures which in turn gives a more water-wet coal surface, i.e. the observed behaviour is different than previously reported behaviour [26].

Specifically, for the high rank coal (semi-anthracite), the zeta potential increased from -23.1 $\mathrm{mV}$ to $2.63 \mathrm{mV}$ when temperature increased from $298 \mathrm{~K}$ to $343 \mathrm{~K}$ (Figure 1). For the same temperature increase, $\theta_{\mathrm{a}}$ decreased from $59^{\circ}$ to $32^{\circ}$ and $\theta_{\mathrm{r}}$ decreased from $52^{\circ}$ to $27^{\circ}$ (Figure 2). Similar trends were found for medium and low rank coals i.e. the zeta potentials of coal/DI water increased with temperature (Figure 1) and corresponding $\theta_{\mathrm{a}}$ and $\theta_{\mathrm{r}}$ decreased with temperature. For instance, for the medium rank coal (medium volatile bituminous), the zeta 
potential increased from $-24.8 \mathrm{mV}$ to $0.236 \mathrm{mV}$ when temperature increased from $298 \mathrm{~K}$ to $343 \mathrm{~K}$, and correspondingly, $\theta_{\mathrm{a}}$ decreased from $40^{\circ}$ to $18^{\circ}$ and $\theta_{\mathrm{r}}$ decreased from $33^{\circ}$ to $12^{\circ}$ (Figure 2).

On the coal surface, ionisable groups are present (e.g. phenolic and carboxylic groups, [27]), thus, as temperature increases and the $\mathrm{pH}$ decreases $(\mathrm{pH}$ decreases with temperature due to reduction in $\mathrm{pK}$ values of water and also due to a reduction in hydrogen bonding leading to increased number of protons $\left(\mathrm{H}^{+}\right)$; [28]), the released protons $\left(\mathrm{H}^{+}\right)$interact with the surface functional groups and ionize them, e.g. $\mathrm{C}=\mathrm{O}$ reacts to $\mathrm{C}-\mathrm{OH}^{+}$or $\mathrm{C}-\mathrm{OH}^{+}$reacts to $\mathrm{C}-\mathrm{OH}_{2}{ }^{2+}$ [27]. Therefore the surface of the coal becomes more positive with an increase in temperature, and consequently the zeta potential increases. Moreover, it is also reported that with increase in temperature, surface oxidation is accelerated and hydrophilic groups are formed on the coal surface at high temperature [29-31] which may lead to lower water contact angles with increasing temperature. However, we believe that oxidation of coal surfaces require sufficient exposure time which is likely to be well beyond the timescale of surface exposure to high temperature during our contact angle measurements [32]. Thus, we point out that oxidation may not be a governing factor for the decrease in contact angle with temperature despite a corresponding increase in zeta potential. We believe that further research is required to explore this effect.

Somasundaran et al. [31] found that for high volatile bituminous coal (from Pennsylvania), the magnitude of zeta potential decreased with temperature (at a $\mathrm{pH}$ of 6.78 , zeta potential measured $-26 \mathrm{mV}$ at $300 \mathrm{~K}$ and reduced to $-20 \mathrm{mV}$ at $363 \mathrm{~K}$ ). At the same $\mathrm{pH}$ (6.78, Table 2), the zeta potential of our medium rank coal (medium volatile bituminous) measured $-24.8 \mathrm{mV}$ at $298 \mathrm{~K}$ in good agreement with Somasundaran et al. [31]. The slight difference is probably due to the slightly different coal and associated differences in coal surface chemistry. Because of the limited literature data on zeta potential of coals, we compared our data with coals of similar ranks (if not exactly the same) despite their origin from a different basin (e.g. Somasundaran's coal from Pennsylvania is compared to our coal sample from West Virgina).

The observed increase in zeta potential with increasing temperature is attributed to the reduction in $\mathrm{pH}$ (with increasing temperature), consistent with Vinogradov and Jackson [33], who reported that zeta potentials of sandstones decreased in magnitude with increasing temperature for low salinity brine ( $0.6 \mathrm{wt} \% \mathrm{NaCl}$ to $3 \mathrm{wt} \% \mathrm{NaCl})$, and they concluded that $\mathrm{pH}$ reduction with increasing temperature was responsible for the zeta potential variation. Note: 
241 The coals are compared with quartz (Vinogradov and Jackson's [33] work) because mineralogy

242 of these coals revealed that quartz is a significant component of these coals (XRD results, Table $2433)$.

244 To further explain the charge reversal behaviour, we conducted $\mathrm{pH}$ measurements of the 245 solutions at high temperatures and found that $\mathrm{pH}$ dropped only slightly (e.g. for lignite/water 246 solution $\mathrm{pH}=6.5$ at $323 \mathrm{~K}$ and $\mathrm{pH}=6.32$ at $343 \mathrm{~K}$ ), thus zeta potentials are only slightly 247 impacted by $\mathrm{pH}$ changes. Therefore, divalent ions could possibly be acting as potential 248 determining ions.

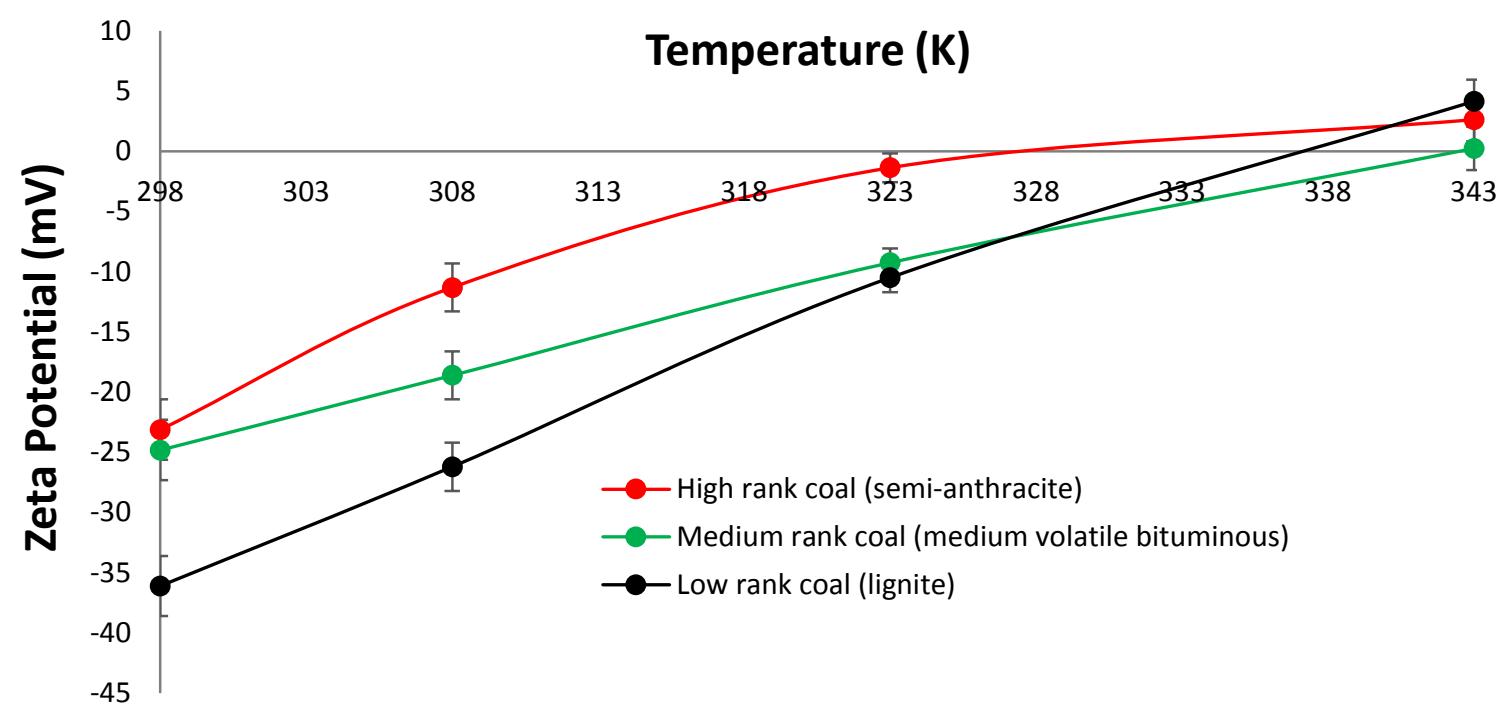

251 Figure 1. Zeta potential as a function of temperature and coal rank (at ambient pressure). 


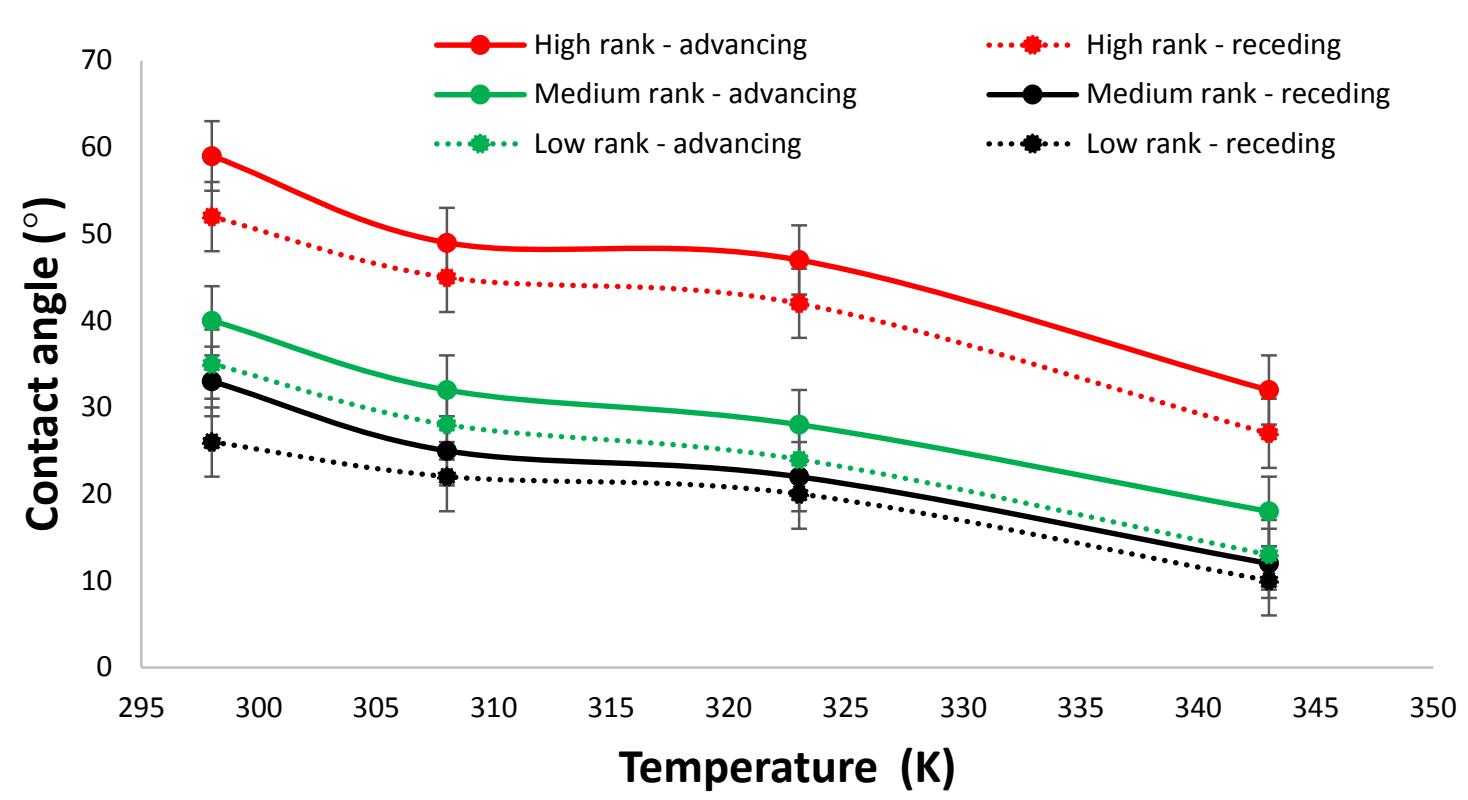

253

254 Figure 2. Water contact angle as a function of temperature and coal rank (at ambient pressure).

256 We further found that at any given temperature, high rank coal exhibited higher values of zeta 257 potential and higher water contact angles than low rank coals. For instance, at $323 \mathrm{~K}$, the zeta potential measured $-1.36 \mathrm{mV}$ for the high rank coal, $-9.25 \mathrm{mV}$ for medium rank coal, and 10.5 $\mathrm{mV}$ for low rank coal (Figure 1$)$, while the associated contact angles were $\left(\theta_{\mathrm{a}}=47^{\circ}, 28^{\circ}\right.$ and $24^{\circ}$ and $\theta_{\mathrm{r}}=42^{\circ}, 23^{\circ}$ and $20^{\circ}$ for high, medium and low rank coals respectively). This behaviour is attributed to the lack of hydrophilic function groups ( $\mathrm{OH}$ groups) in high rank coals (further discussed in Section 3.5).

Considering the above electrochemical behaviour of coals at ambient pressure, we now consider $\mathrm{CO}_{2}$ /brine/coal contact angle data at high pressure (15 $\mathrm{MPa}$ ) from our previous work (Arif et al., 2016c, [12]). It was found that at $15 \mathrm{MPa}$, for high rank coal, when temperature increased from $308 \mathrm{~K}$ to $323 \mathrm{~K}, \theta_{\mathrm{a}}$ decreased from $146^{\circ}$ to $119^{\circ}$, implying a wettability transformation from strongly $\mathrm{CO}_{2}$-wet to weakly $\mathrm{CO}_{2}$-wet. Similarly, for medium rank coal, $\theta_{\mathrm{a}}$ decreased from $128^{\circ}$ to $102^{\circ}$ when temperature increased from $308 \mathrm{~K}$ to $343 \mathrm{~K}$. However, for low rank coal, $\theta_{\mathrm{a}}$ first decreased from $112^{\circ}$ to $102^{\circ}$ when temperature increased from $308 \mathrm{~K}$ to $323 \mathrm{~K}$, and then became constant when temperature increased further (from $323 \mathrm{~K}$ to $343 \mathrm{~K}$;

271 [12]). In summary, water-wettability of coal increased with increasing temperature irrespective 272 of the coal rank. Thus, the effect of temperature on wettability is similar at high pressure as 273 that found at ambient pressure (i.e. air/brine contact angles at low pressure and $\mathrm{CO}_{2} /$ brine 
contact angles at high pressure followed similar trend). It can therefore be concluded that the temperature dependence of $\mathrm{CO}_{2}$-wettability of coals is considerably controlled by electrochemical changes at the water/coal interface and that increase in temperature render the coal surface more water-wet due to formation of ionized surface functional groups.

\subsection{Effect of salinity on zeta potential and contact angle}

The effect of salinity on zeta potential and contact angle was studied as a function of brine salinity ( $0 \mathrm{wt} \% \mathrm{NaCl}, 1 \mathrm{wt} \% \mathrm{NaCl}$ and $5 \mathrm{wt} \% \mathrm{NaCl}$ ) at constant temperature (323 K). It was found that zeta potential increased with an increase in salinity for all coal ranks (Figure 3). Moreover, both $\theta_{\mathrm{a}}$ and $\theta_{\mathrm{r}}$ increased with salinity for all coal samples (Figure 4). Specifically, for the high rank coal, when salinity increased from $0 \mathrm{wt} \% \mathrm{NaCl}$ to $5 \mathrm{wt} \% \mathrm{NaCl}$ (or equivalently from $0 \mathrm{M}$ to $0.855 \mathrm{M}$ ), zeta potential increased from $-1.63 \mathrm{mV}$ to $2.63 \mathrm{mV}$. For the same salinity increase, $\theta_{\mathrm{a}}$ increased from $47^{\circ}$ to $60^{\circ}$ and $\theta_{\mathrm{r}}$ increased from $42^{\circ}$ to $53^{\circ}$ (Figure 4). Similarly, for medium rank coal, the zeta potential increased from $-9.25 \mathrm{mV}$ to $0.263 \mathrm{mV}$ when salinity increased from $0 \mathrm{wt} \% \mathrm{NaCl}$ to $5 \mathrm{wt} \% \mathrm{NaCl}$, indicating a clear increase in zeta potentials with increasing salinity, and the corresponding values of $\theta_{a}$ increased from $28^{\circ}$ to $41^{\circ}$ and $\theta_{\mathrm{r}}$ increased from $22^{\circ}$ to $35^{\circ}$ (Figure 4 ). Generally, for any solid/brine system, the composition of solid and the concentration and valency of ions in the solution are responsible for the sign and value of the zeta potential [34]. Physically, the coal surface exhibits negative charges due to the presence of polar functional entities, which partially dissociate, e.g. carboxylic or phenolic groups [35]; the concentration of these functional groups depends on the coal rank ([36] see also FTIR discussion in Section 3.5). The results found here are consistent with Ibrahim and Nasr-El-Din [37] who reported that both zeta potentials and contact angles on coals increased with salinity. Fuerstenau et al. [38] reported that for low ash anthracite coal, the zeta potential was measured to be $-25 \mathrm{mV}$ at $0.01 \mathrm{M} \mathrm{NaCl}(\mathrm{pH}=7)$ at room temperature. We found that for high rank coal (semi-anthracite) at (almost) the same $\mathrm{pH}$ (7.09, Table 2), the zeta potential was measured to be $-23 \mathrm{mV}$ (Figure 1) indicating consistent results. Harvey et al. [39] also found an increase in zeta potential of coal with salinity. They reported that for sub-bituminous (medium rank) coal, at a $\mathrm{pH}$ of 8, zeta potential increased from $-32 \mathrm{mV}$ to $-25 \mathrm{mV}$ when salinity changed from $0 \mathrm{wt} \% \mathrm{NaCl}$ (DI-water) to $0.5 \mathrm{wt} \% \mathrm{NaCl}$ at room temperature. For a similar bituminous coal we also measured an increase in zeta potential at 323K (-9.25 mV for DI-water decreased to $-8.5 \mathrm{mV}$ for $0.5 \mathrm{wt} \% \mathrm{NaCl}$ brine, Figure 3). Roshan 


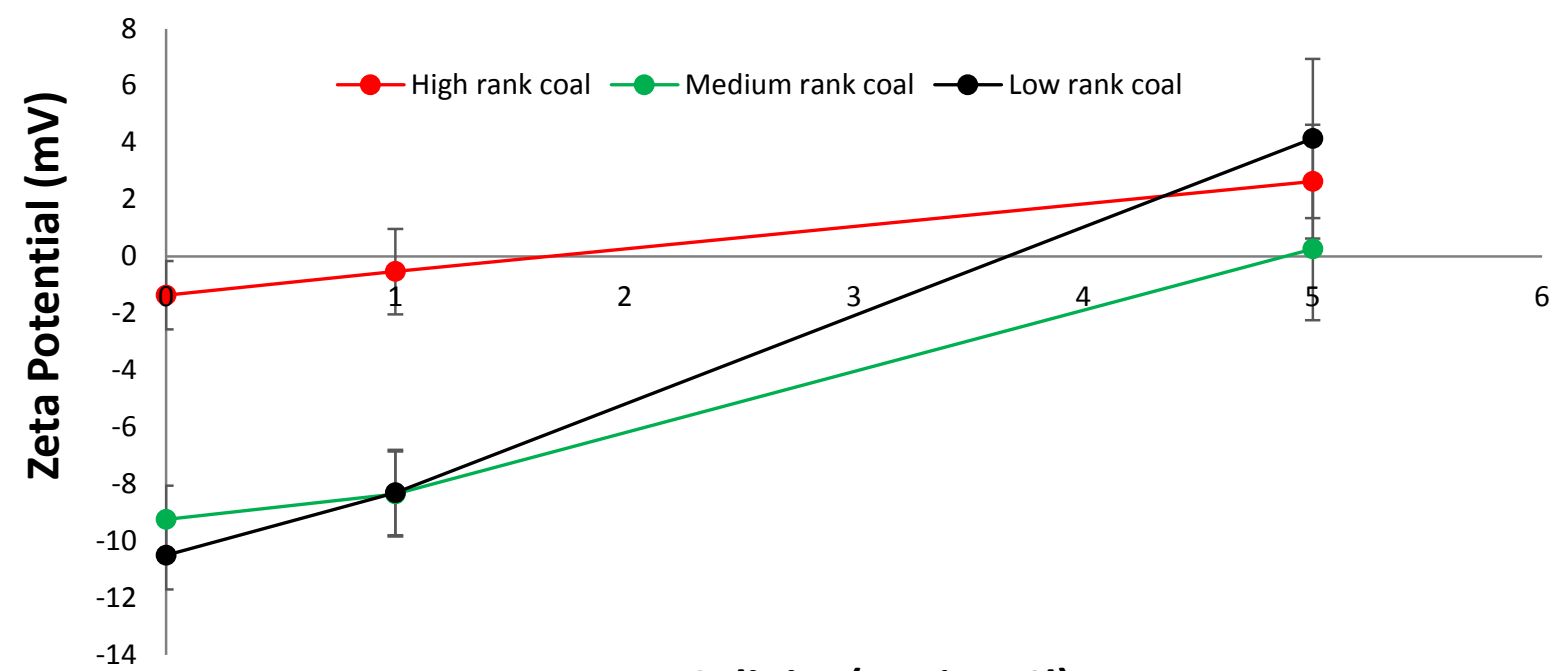

315

316 Figure 3. Effect of salinity on zeta potential at $323 \mathrm{~K}$ (and ambient pressure) as a function of

et al. [40] recently introduced a model to describe the physical processes for wettability variation as a function of salinity and they related the contact angle to the electric potential at the mineral surface. According to their explanation, the dielectric constant of the fluid decreases with increasing salinity, which leads to an increased contact angle. The decrease in zeta potential correlates with the charge on the surface being more screened as more ions are present in the double layer, this leads to an increased water contact angle [41].

\section{Salinity (wt\% $\mathrm{NaCl})$}




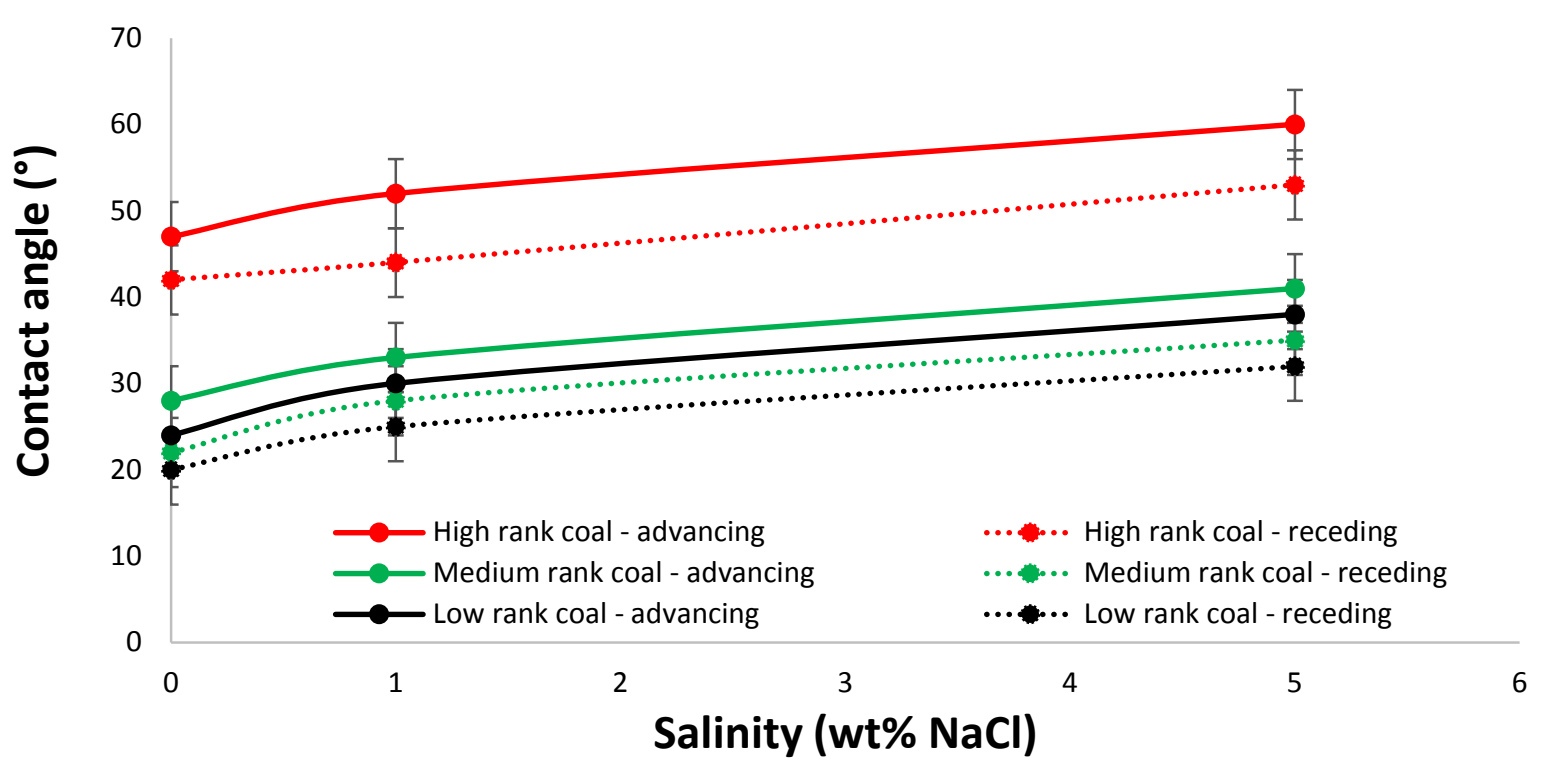

320 Figure 4. Water contact angle as a function of salinity and coal rank at $323 \mathrm{~K}$ (and ambient pressure).

Mechanistically, with the increase in ionic strength, the number of counter ions on the surface increases, which screens the surface charge (and thus results in a reduction of the thickness of the Debye layer). This means that the zeta potential decreases with increasing salt concentration. It is also notable that for the high rank coal, at a salinity of approximately 1.8 $\mathrm{wt} \% \mathrm{NaCl}$ the zeta potential is zero, while for low rank coal $3.7 \mathrm{wt} \% \mathrm{NaCl}$ (Figure 3) is required to reach the point of zero zeta potential. The shift in salinity at which a zero charge is obtained varies between high, medium and low rank coal and is associated with the relative affinity of the respective coal surface for $\mathrm{H}^{+}$and $\mathrm{OH}^{-}$ions (which varies with coal rank [23], and again is related to the concentration of surface functional groups, see FTIR discussion in Section 3.5). The salt content for achieving a zero charge as reported here is also of important consideration for processes that involve colloidal dispersion and coagulation [35], e.g. in coal processing [42].

Further, we compared zeta potentials to advancing and receding contact angles measured at high pressure (15 MPa and $323 \mathrm{~K}$, Arif et al. [12]). For all coal ranks, both, $\theta_{\mathrm{a}}$ and $\theta_{\mathrm{r}}$, increased with salinity at high pressures (Arif et al. [12]). For medium rank coal, at $15 \mathrm{MPa}$ and $323 \mathrm{~K}$, $\theta_{\mathrm{a}}$ increased from $114^{\circ}$ to $127^{\circ}$ and $\theta_{\mathrm{r}}$ increased from $102^{\circ}$ to $112^{\circ}$ when salinity increased from $0 \mathrm{wt} \% \mathrm{NaCl}$ to $5 \mathrm{wt} \% \mathrm{NaCl}$ brine. For a salinity increase from $5 \mathrm{wt} \% \mathrm{NaCl}$ to $10 \mathrm{wt} \% \mathrm{NaCl}$, $\theta_{\mathrm{a}}$ increased from $127^{\circ}$ to $132^{\circ}$ and $\theta_{\mathrm{r}}$ increased from $112^{\circ}$ to $116^{\circ}$. Moreover, we found similar 
trends for low and high rank coals. Considering the fact that the trends of contact angle variation with temperature, salinity, and rank at high pressures were same as those at ambient conditions, it can be hypothesized that zeta potentials might also follow similar trends at high pressures (in a coal/ $/ \mathrm{CO}_{2} /$ brine system) as we showed in this work at ambient pressure (in a coal/air/brine system).

\subsection{Effect of brine composition on zeta potential and contact angle}

The effect of salt type on zeta potential and contact angles was analysed by measuring zeta potentials and contact angles for coal/brine systems at $323 \mathrm{~K}$ and ambient pressure for three brines $1 \mathrm{wt} \% \mathrm{NaCl}(0.17 \mathrm{M}), 1 \mathrm{wt} \% \mathrm{CaCl}_{2}(0.27 \mathrm{M})$ and $1 \mathrm{wt} \% \mathrm{MgCl}_{2}(0.305 \mathrm{M})$ for all coal ranks investigated. To facilitate the comparison of salt types, we have plotted zeta potential as a function of salt type in two formats: a) in terms of salt concentration in wt\%, and b) in terms of the ionic strength of the solution (Figure $5 \mathrm{a}$, and b). We found that from $\mathrm{Na}$ to $\mathrm{Ca}$ to $\mathrm{Mg}$ brine types, at the same salinity and temperature, the zeta potential increased (Figure 5a) and contact angle also increased for all coal ranks (Figure 6). Specifically, for instance, for medium rank coal the zeta potential at the interface of coal $/ 1 \mathrm{wt} \% \mathrm{NaCl}$-brine measured $-8.3 \mathrm{mV}$, while at the coal $/ 1 \mathrm{wt} \% \mathrm{CaCl}_{2}$-brine interface it measured $-3.09 \mathrm{mV}$, and at coal $/ \mathrm{MgCl}_{2}$-brine interface it measured $-2.65 \mathrm{mV}$ indicating an increase in zeta potential with increasing cation charge-to-volume ratio (which is $2.61 \times 10^{-7} \mathrm{C}_{\mathrm{pm}}{ }^{-3}$ for $\mathrm{Na}^{+}, 4.92 \times 10^{-7} \mathrm{C} . \mathrm{pm}^{-3}$ for $\mathrm{Ca}^{+}$and $1.66 \times 10^{-6} \mathrm{C}^{-\mathrm{pm}^{-3}}$ for $\mathrm{Mg}^{+}$, [43]). At the ionic strength of $0.27 \mathrm{M}(1.58 \mathrm{wt} \%) \mathrm{NaCl}$, the zeta potential can be interpolated from Figure 3 (corresponding to $1.58 \mathrm{wt} \% \mathrm{NaCl}$ ) to facilitate comparison at exactly the same ionic strength as that of $\mathrm{Ca}$ and $\mathrm{Mg}$ based salts.

The negative values of the coal zeta potentials can be attributed to dissociation of surface functional groups (e.g. $-\mathrm{COOH}$ ) [44]. The positive zeta potential values obtained are attributed to the surface charge screening effect due to counter ions provided by the cations of the salt as discussed above. Moreover, $\theta_{\mathrm{a}}$ increased from $52^{\circ}$ to $60^{\circ}$ and $\theta_{\mathrm{r}}$ increased from $44^{\circ}$ to $53^{\circ}$ when brine composition changed from $1 \mathrm{wt} \% \mathrm{NaCl}$ to $1 \mathrm{wt} \% \mathrm{MgCl}_{2}$ (Figure 6). The results are consistent with [37] who also reported that coal/brine zeta potentials increased for divalent cations $\left(\mathrm{Ca}^{2+}\right.$ and $\left.\mathrm{Mg}^{2+}\right)$. Harvey et al. [39] also found that $\mathrm{MgCl}_{2}$ brine resulted in an increase in zeta potential. 


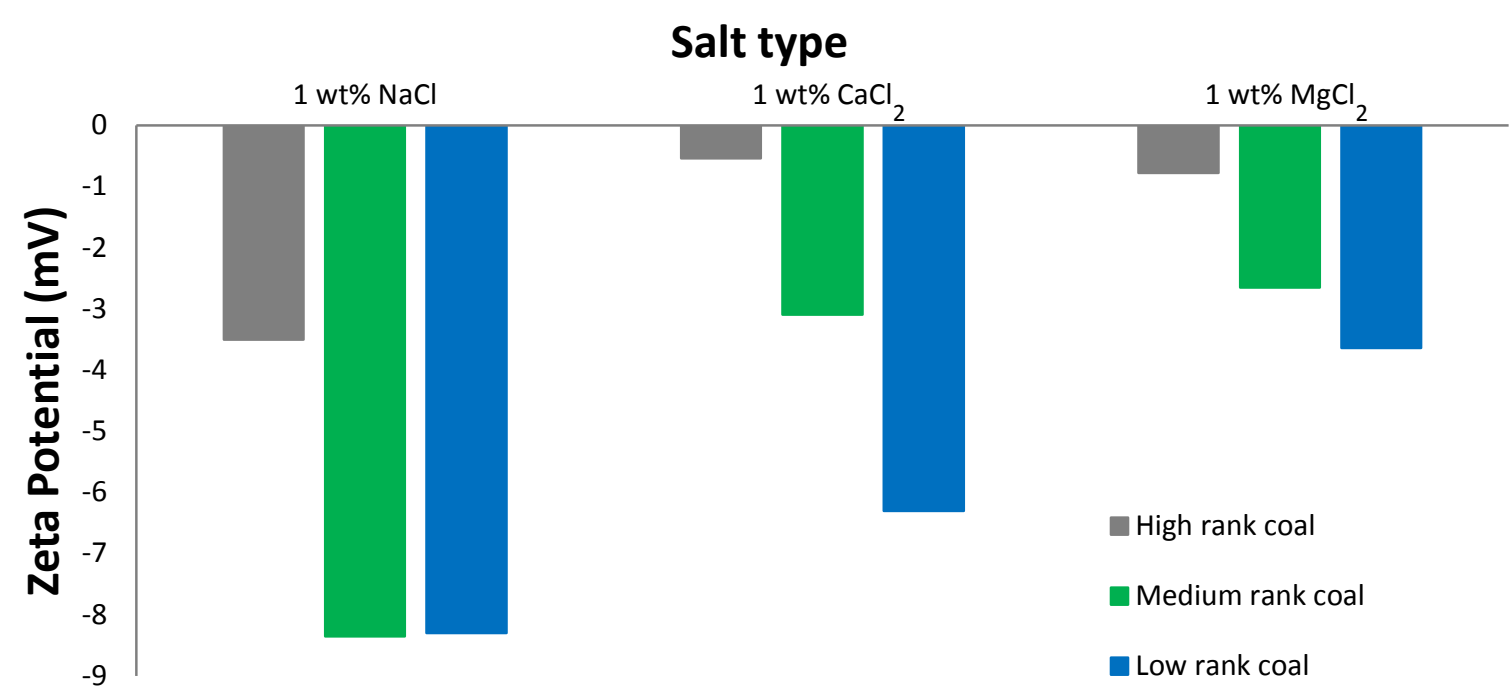

a)

\section{Type of brine}

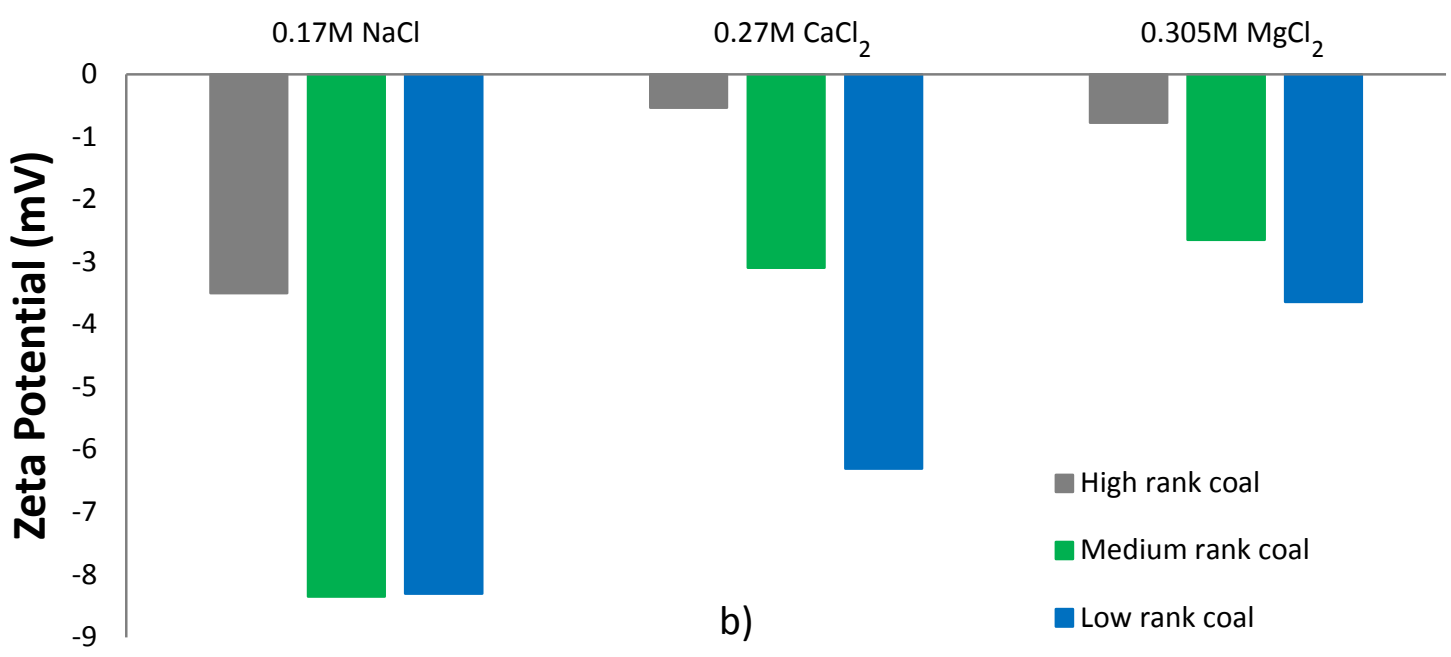

374 Figure 5. Zeta potential as a function of salt type $\left(\mathrm{NaCl}, \mathrm{CaCl}_{2}, \mathrm{MgCl}_{2}\right)$ and coal rank (at 323

$375 \mathrm{~K}$ and ambient pressure). Data is shown in two formats: a) In terms of concentration in wt\%, 376 b) In terms of ionic strength of brine 


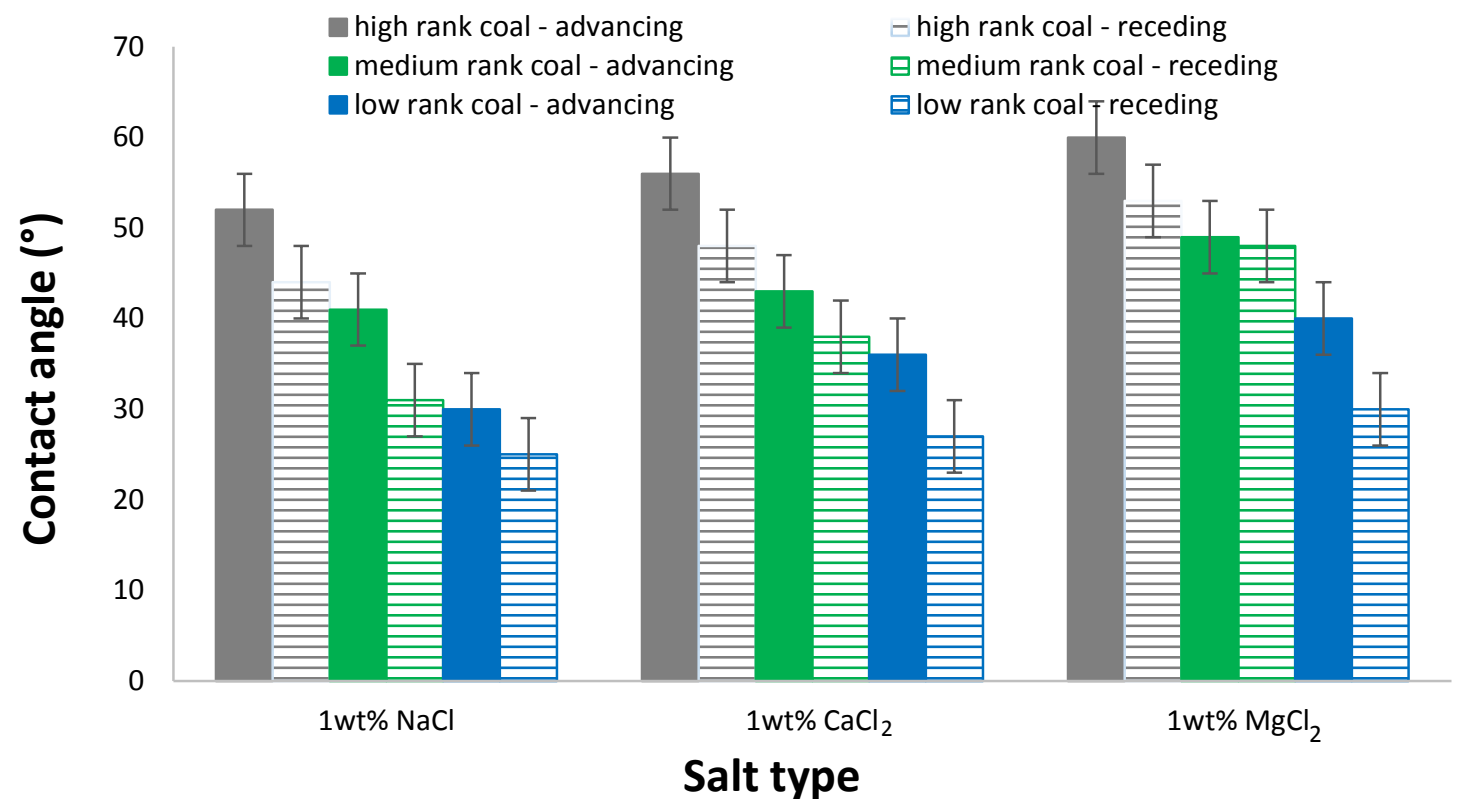

380 Figure 6. Water contact angle as a function of salt type $\left(\mathrm{NaCl}, \mathrm{CaCl}_{2}, \mathrm{MgCl}_{2}\right)$ and coal rank 381 (at $323 \mathrm{~K}$ and ambient pressure).

To investigate the impact of coal rank on zeta potential and wettability, the results shown in Figures 1-6 are reconsidered briefly. At any temperature (except $343 \mathrm{~K}$ ), the zeta potential of the coal/water system increased with increasing rank (Figure 1). For instance, at $308 \mathrm{~K}$, the zeta potential was $-26.2 \mathrm{mV}$ for low rank coal (lignite, $\mathrm{R}_{0}=0.35 \%$ ), $-18.6 \mathrm{mV}$ for medium rank coal (medium volatile bituminous, $\mathrm{R}_{0}=0.82 \%$ ) and $-11.3 \mathrm{mV}$ for high rank coal (semianthracite, $\left.\mathrm{R}_{0}=3.92 \%\right)$. This is consistent with Abotsi et al. [45] who found that at a $\mathrm{pH}>5.5$ low rank coal had more negative zeta potential values in DI water at room temperature. For instance, they reported that at a $\mathrm{pH}=6.5$, zeta potentials of lignite (North Dakota) were -40 $\mathrm{mV}, \sim-30 \mathrm{mV}$ for sub-bituminous and $\sim-20 \mathrm{mV}$ for bituminous coals which is quite comparable to our results (at $298 \mathrm{~K}$, zeta potentials measured $-36 \mathrm{mV}$ and $-25 \mathrm{mV}$ for low and medium rank coals, respectively).

As the coal rank increases, the zeta potential increases, indicating a diminishing number of polar surface sites (a proportion of which are negatively charged due to dissociation), [42].

397 This results in a strong dependence of the isoelectric point (the $\mathrm{pH}$ at which the surface carries no net charge) and the sign of the zeta potential on the carbon content (i.e. the coal rank, [46]). 
In addition, aqueous cationic ion concentrations increase due to dissociation of groups capable of forming ions or decrease by re-adsorption of some dissolved ions on the solid particle surface [47]. Consequently the electrical double layer on the particle becomes thinner or thicker, which induces a change in zeta potential. In the case of coal, the high mineral content and dissociation of ionogenic groups on the (complex) coal surface [48] leads to different charges on coals of different ranks (low zeta potentials for low rank coal and high zeta potentials for high rank coal).

We relate the variation in zeta potential as a function of coal rank to the mineralogy of coal. In this context, we note that the major components of the coals are quartz and kaolinite (XRD results, Table 3). The low rank coal contains $76 \%$ quartz and $24 \%$ kaolinite. At room temperature, we find from Kaya and Yukselen [49] that zeta potential of quartz/water and kaolinite/water were both negative for a wide range of tested $\mathrm{pH}$ and that quartz/water zeta potential was much lower than that of the kaolinite/water (e.g. at $\mathrm{pH}$ of 6.8, zeta potentials were $-52 \mathrm{mV}$ for quartz and $-34 \mathrm{mV}$ for kaolinite). Thus our measured value of zeta potential of lignite which was $-36.1 \mathrm{mV}$ at room temperature is in accordance to the mineralogy of lignite i.e. the zeta potential of lignite is comparable to individual mineral's zeta potentials. Moreover the percentages of quartz and kaolinite were $41 \mathrm{wt} \%$ and $30 \mathrm{wt} \%$ in medium rank coals, and $21 \mathrm{wt} \%$ and $24 \mathrm{wt} \%$ in high rank coals (Table 3). The measured values of zeta potential of medium and high rank coal at $298 \mathrm{~K}$ were $-24.8 \mathrm{mV}$ and $-23.1 \mathrm{mV}$. The impact of minerology is thus clear in the sense that the increase in percentage of quartz and kaolinite in coal leads to a reduction in zeta potential (low rank coal has lower zeta potential because of higher quartz and kaolinite content).

The decrease in negative charge density on the coal surface with increasing coal rank is attributed to the increase in fixed carbon (\%) and a decrease in oxygen content with rank [50], Table 1 . We note that high and medium rank coal demonstrated similar trend of zeta potential variation as a function of salinity but low rank coal showed slightly inconsistent behaviour as a function of salinity at higher salinity $(5 \mathrm{wt} \% \mathrm{NaCl})$ which can be attributed to the presence of more hydrophilic groups (OH groups) in low rank coals, Figure 3).

The surface charge on coal in the presence of electrolytes is induced by ionization or protonation of the surface carboxylic and hydroxyl groups; note that the dissociation of carboxylic groups is enhanced in the presence of $\mathrm{OH}^{-}$[51]. 


$$
-\mathrm{COH}_{2}^{+} \stackrel{\mathrm{H}^{+}}{\longleftarrow}-\mathrm{COH} \stackrel{\mathrm{OH}^{-}}{\longrightarrow}-\mathrm{CO}^{-}+\mathrm{H}_{2} \mathrm{O}
$$

\subsection{Surface functional group characterization and associated hydrophobicity of coals}

434 In order to assess the factors responsible for the wetting behaviour of the $\mathrm{coal} / \mathrm{CO}_{2} / \mathrm{brine}$ systems, we consider experimental data for water advancing and receding contact angle from our previous work (Arif et al. [12]), Figure 7. It can be seen that water wettability of coals decreases with increasing pressure and increasing rank. At any given $\mathrm{CO}_{2}$ pressure, the high rank coal had the highest water contact angle which means that these coals are less water-wet. Low rank coals (e.g. lignite) are more water-wet and medium rank coal (e.g. bituminous) are intermediate-wet. These results are in agreement with Shojai Kaveh et al. [15] who compared $\mathrm{CO}_{2}$-wettability of semi-anthracite and high volatile bituminous coals, and they measured higher contact angles for semi-anthracite coals, and thus they concluded that hydrophobicity of coals increases with coal rank. However, the surface functional groups responsible for such wetting behaviour were unclear. We thus conducted FTIR (Fourier transformed infrared) spectroscopy measurements on the three coal samples, the results are presented in Figure 8.

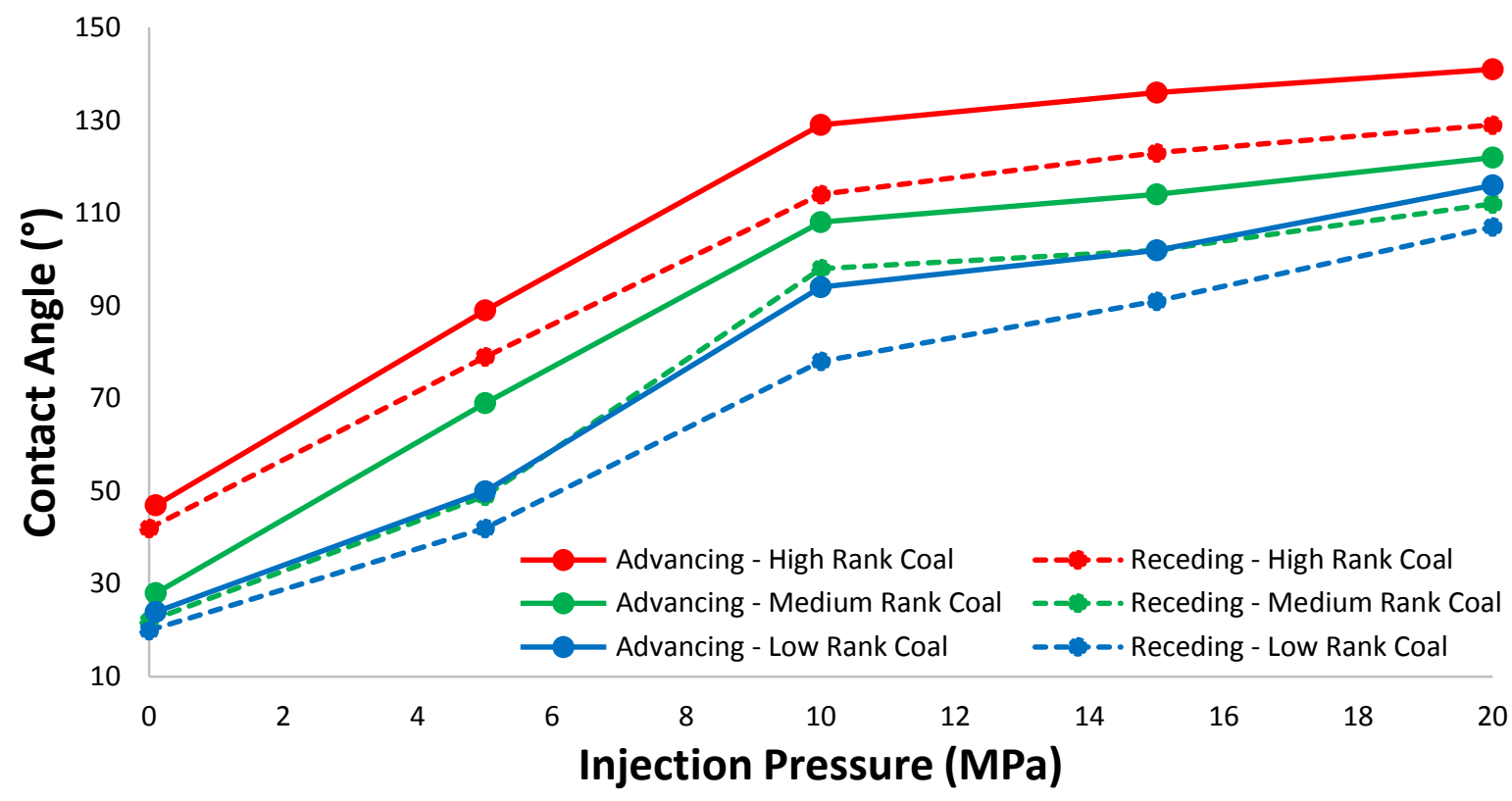

Figure 7. Water contact angle as a function of pressure and coal rank at $323 \mathrm{~K}$ (experimental data from Arif et al. [12]). 
450 High rank coal (semi-anthracite) demonstrated a rather smooth FTIR intensity response 451 throughout the observed wavenumber spectrum, with only small bands observed at a wavenumber range of at $600-800 \mathrm{~cm}^{-1}$ due to a possible C-S stretching vibration, the 1000$1100 \mathrm{~cm}^{-1}$ due to $\mathrm{C}-\mathrm{H}$ out of plane bending and $\mathrm{Si}-\mathrm{O}-\mathrm{H}$ asymmetric stretch vibrations and a minute band at $\sim 3800 \mathrm{~cm}^{-1}$ due to $-\mathrm{OH}$ and $\mathrm{N}-\mathrm{H}$ bond stretching vibrations [52,53]; considering the fact that XRD confirmed the presence of Si (Table 3) and elemental analysis confirmed the presence of sulphur and nitrogen (Table 1). The rough part of the spectra for 2000-2400 $\mathrm{cm}^{-1}$ should be ignored as this is where the ATR crystal is absorbing itself (diamond) and the bands don't always perfectly cancel out. From the stand point of surface functional groups and associated wetting behaviour, the absence (or only minute presence) of hydrophilic sites e.g. OH groups in high rank coal is responsible for its hydrophobic behaviour $\left(\theta>130^{\circ}\right.$, Figure 7$)$.

On the contrary, medium rank coal (medium volatile bituminous) exhibited significantly stronger bands (in comparison to high rank coal) at wave numbers from $600-800 \mathrm{~cm}^{-1}$ and 1000 $1100 \mathrm{~cm}^{-1}$ indicating the presence of more C-S stretching vibrations and C-H out of plane bending. Moreover, medium rank coal also exhibited larger bands at $\sim 3600-3700 \mathrm{~cm}^{-1}$ which is attributed to $\mathrm{O}-\mathrm{H}$ and $\mathrm{N}-\mathrm{H}$ stretch vibrations. Furthermore, distinct bands were observed at 2800-2900, and 1500-1700 $\mathrm{cm}^{-1}$ which are due to $\mathrm{C}=\mathrm{C}$ and $\mathrm{C}=\mathrm{O}$ stretch vibrations respectively [53]. Thus, the presence of more hydrophilic sites (OH groups) in medium rank coal renders it relatively less $\mathrm{CO}_{2}$-wet in comparison to high rank coal (e.g. for instance at $10 \mathrm{MPa}, \theta_{\mathrm{a}}=108^{\circ}$ for medium rank coal in comparison to $129^{\circ}$ for high rank coal, Figure 7).

Low rank coal demonstrated the largest peak beginning at about $2800 \mathrm{~cm}^{-1}$ and ending at 3800 $\mathrm{cm}^{-1}$ which is attributed to the $\mathrm{O}-\mathrm{H}$ and $\mathrm{N}-\mathrm{H}$ stretch vibrations and this largest peak is responsible for the hydrophilic nature of lignite coal even at high pressures (Figure 7). The band at $\sim 2900 \mathrm{~cm}^{-1}$ observed for low rank coal is due to the presence of aliphatic C-H stretching vibrations [36]; however, its absence in high rank coal is unusual and is perhaps due to C-H stretching where the carbon is in a $\mathrm{C}=\mathrm{C}$ bond. Moreover, the sharp band observed at 1500$1800 \mathrm{~cm}^{-1}$ for low rank coal is attributed to aromatic ring vibrations, which are enhanced by oxygen groups [35]. The corresponding shoulder peaks at $1600 \mathrm{~cm}^{-1}$ is attributed to $\mathrm{C}=\mathrm{O}$ stretching vibrations and these represent all $\mathrm{C}=\mathrm{O}$ functionalities, e.g. carboxylic acids or 
485

486 487

488

increase in hydrophilicity of the coals' surface and that is evident from the contact angle data (e.g. lignite is relatively more water-wet as compared to bituminous and anthracite coals, Figure 7).

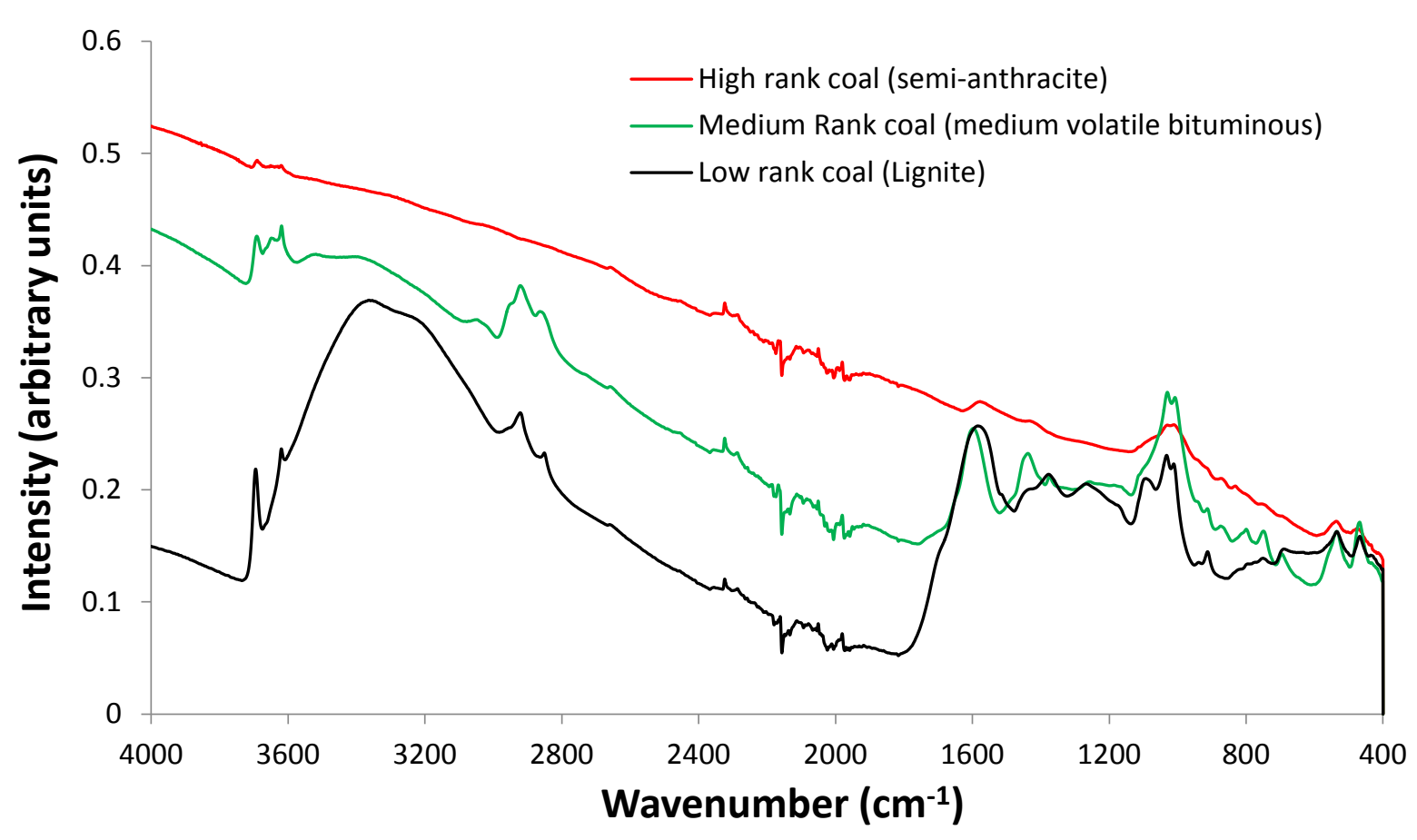

Figure 8. ATR-infrared spectroscopy measurements on low, medium and high rank coals

In summary, the much lower number of Si-OH, hydroxyl, ester, and carboxylic groups in high rank coal is responsible for its hydrophobic behaviour. On the contrary, the abundance of these groups (especially $\mathrm{OH}$ ) is responsible for the hydrophilic nature of low rank coal. Medium rank coal stands somewhere in the middle (consistent with contact angle data; Figure 8). Thus the increase in contact angle (at typical operating conditions) with coal rank (Figure 7, Arif et al. [12]) is adequately explained by surface functional groups.

\subsection{Correlation between zeta potential and coal-wettability}

Our results showed that zeta potential increased with increasing rank and salinity, and contact angle also increased with increasing rank and salinity, implying a positive correlation between zeta potential and coal-wettability, i.e. higher zeta potential correspond to a less water-wet surface (= higher $\theta$ ). In order to demonstrate this relation, we developed a cross plot between 
499 water advancing contact angle and zeta potential as a function of rank (Figure 9a) and as a 500 function of salinity (Figure 9b).

501 Specifically, for any given temperature (298 K-343 K), advancing contact angle increased with 502 the increase in zeta potential (all solid coloured trend lines in Figure 9a) for all coals. Moreover, 503 as salinity increased, zeta potential increased and contact angle also increased (Figure 9b). The 504 overall correlation between zeta potential and wettability is also positive (Figure 9b).

505 However, with respect to temperature, a contradictory trend is found such that as temperature 506 increased zeta potential increased but contact angle decreased (this can be visualized by joining 507 the points of the same symbol in Figure 9a by means of a trend line). The reason for this 508 contradiction is not clearly known yet, however, the possible factors responsible for this 509 deviation could be evaporation at high temperature, and/or the experimental error associated 510 with equipment at high temperatures (which we found was relatively high).

511 On a whole, it appears as if zeta potential is not the primary driver of coal-wettability despite 512 clear positive correlation with respect to salinity and coal rank. Thus it can be established that 513 zeta potential is a secondary factor which controls the coal-wettability variation to some extent. 514 The primary control of wettability is governed by the interfacial interactions of fluids with 515 surface [56] as a function of pressure, temperature and salinity. 


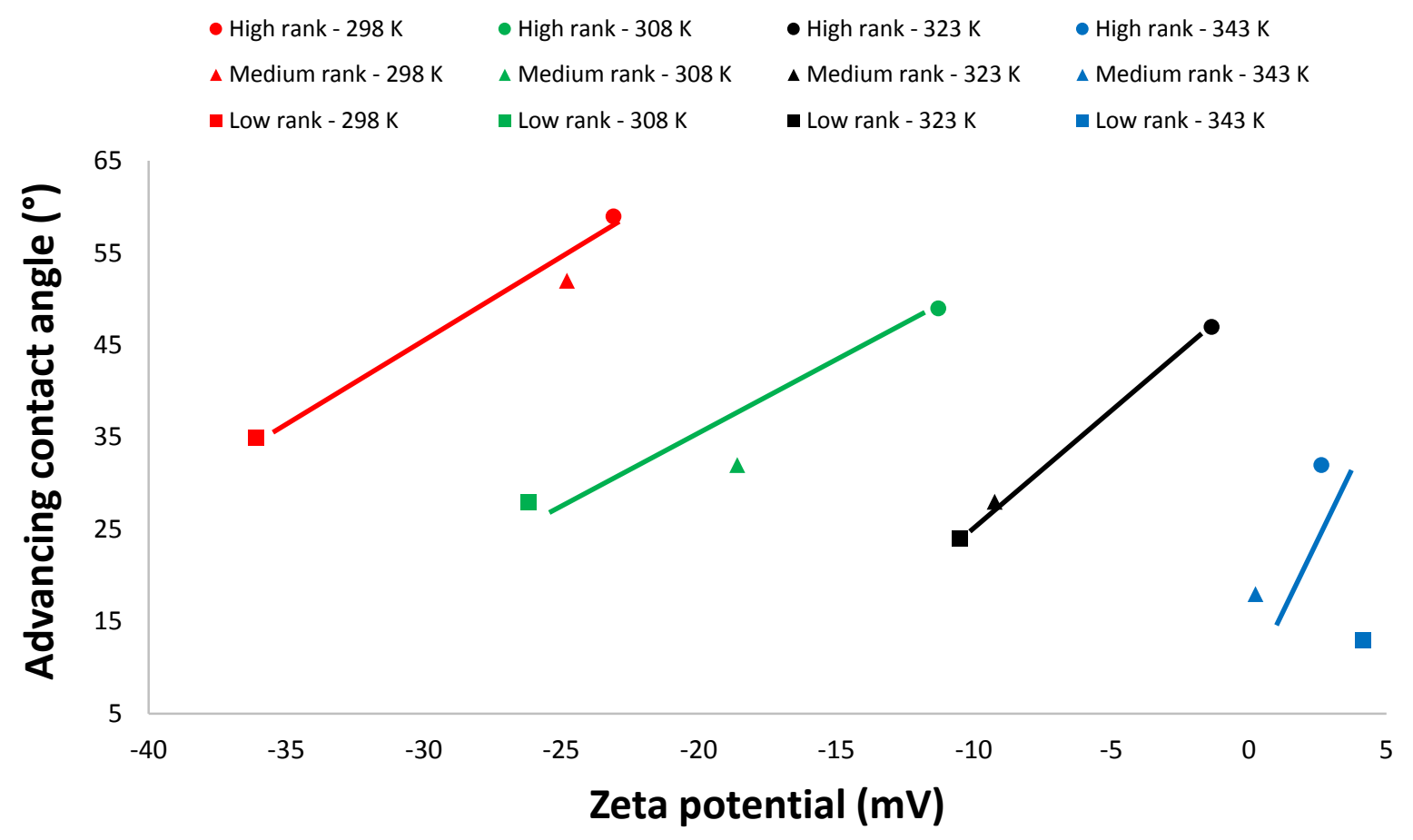

521 Figure 9a. Contact angle-zeta potential cross plot at all temperatures as a function of coal rank.

522 Circle $=$ high rank, triangle $=$ medium rank, square $=$ low rank coal. The colour differentiates

523 the measurements as a function of temperature (red, green, black and blue). The solid lines are 524 the trend lines for relation between zeta potential and wettability as a function of coal rank at 525 isothermal and iso-saline conditions.

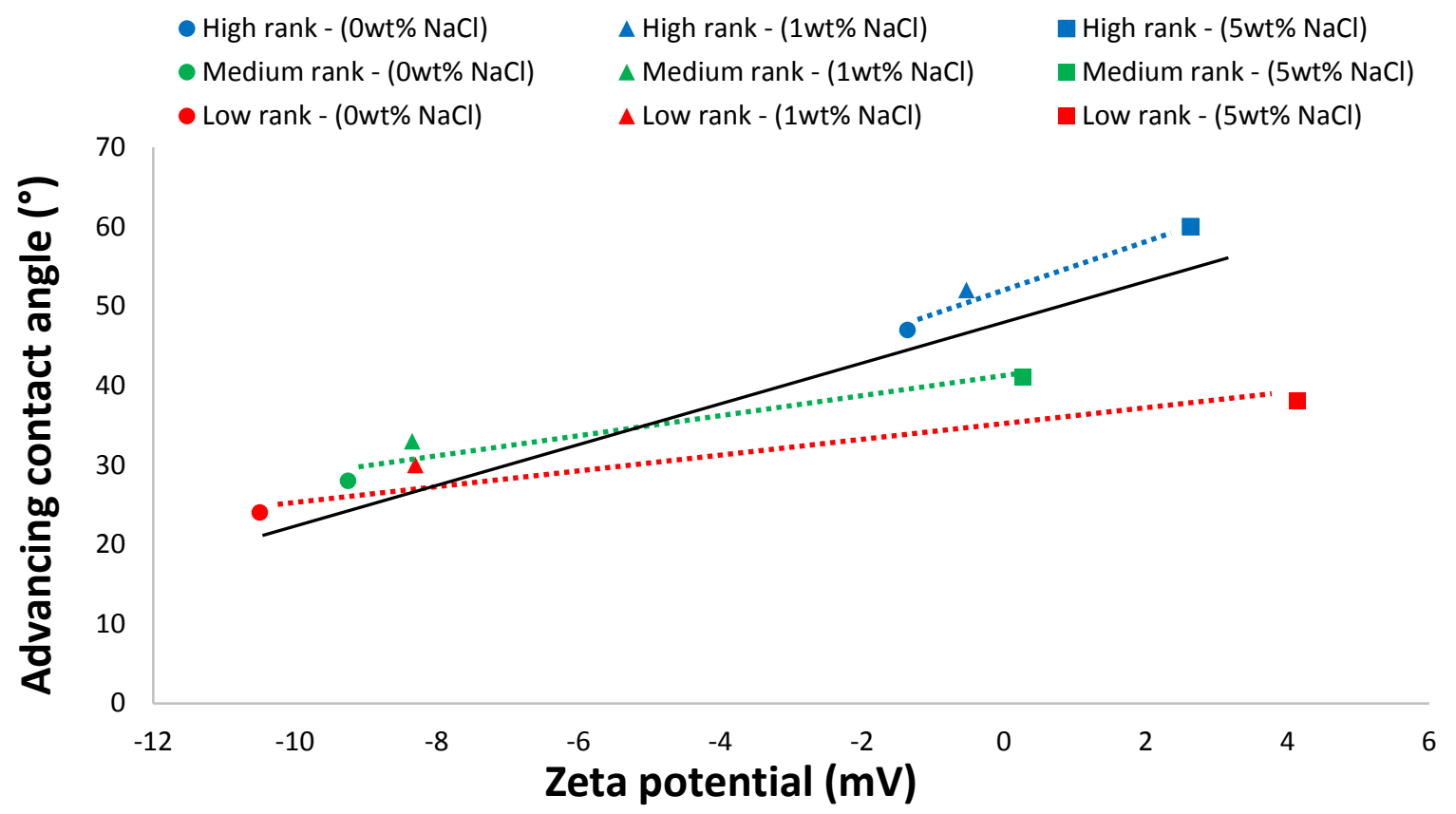

527 Figure 9b. Contact angle-zeta potential cross plot as a function of salinity for all coal ranks at $528323 \mathrm{~K}$. The symbol differentiates the measurements as a function of salinity (Circle: DI-water, 
triangle: $1 \mathrm{wt} \% \mathrm{NaCl}$, square: $5 \mathrm{wt} \% \mathrm{NaCl}$ ). The dotted lines are the trend lines for relation between zeta potential and wettability as a function of salinity for all ranks at isothermal conditions. The solid black line represent the overall trend.

\section{Implications}

In order to assess the factors affecting wetting behaviour of coals, which is of immense importance in terms of understanding micro- and nano-scale fluid dynamics in coal seams, we provided insight into the fluid interactions at the coal/brine interface and their relation with wetting behaviour as a function of temperature, salinity and coal rank. The measured data essentially leads to a better understanding of the mechanism occurring at the pore scale and is, therefore, useful for understanding $\mathrm{CO}_{2}$ storage and (enhanced) methane recovery in coal beds. Zeta potential measurements provide a better understanding of the effect of salinity and rank on wettability, however trend of zeta potential with temperature when correlated with contact angle data was contradictory which needs further investigation. Moreover, the presence of typical surface functional groups (e.g. $\mathrm{OH}$ and carboxylic groups) is responsible for the specific wettability of coals (Figure 7), and this data can thus be used to assess the storage potential of coal seams.

Specifically, we observed that high rank coal was $\mathrm{CO}_{2}$-wet (at reservoir conditions), and thus once injected, $\mathrm{CO}_{2}$ occupies the smallest pores (nano- and micropores in the coal seams) due to its larger affinity to adsorb onto the coal surface $[57,58]$. As a result, methane is displaced towards the production wells and thus leads to improved methane production. However, the lower coal ranks are relatively less suitable for enhanced methane recovery and $\mathrm{CO}_{2}$-storage due to their more water-wet characteristics, which implies poorer adsorption of $\mathrm{CO}_{2}$ onto the coal micro surface [59]. We also point out that with the increase in pressure coal swelling occurs which leads to a reduction in permeability; and this effect limits $\mathrm{CO}_{2}$ injection into coal seams [60].

\section{Conclusions}


558 We measured zeta potentials as a function of temperature and salinity for low, medium and 559 high rank coals. It was found that zeta potential increased with temperature and the water 560 contact angle decreased with temperature. Zeta potentials increased with increasing salinity 561 due to reduction in the thickness of the Debye layer, which occurred because of the surface 562 charge screening by the counter ions. The coal/brine/ $\mathrm{CO}_{2}$ water contact angle also increased 563 with increasing salinity. Furthermore $\mathrm{Mg}^{2+}$ brine demonstrated higher contact angles and 564 higher zeta potentials than those of $\mathrm{Ca}^{2+}$ and $\mathrm{Na}^{+}$brines, and, at any temperature or salinity, 565 high rank coals exhibited high zeta potentials, which is due to their higher carbon content and associated lower surface charge (due to absence of polar functional groups). Zeta potential increased with salinity and rank, and contact angles also increased with salinity and rank, implying a positive relation between zeta potential and wettability. However, the effect of temperature was not conclusive in that the zeta potential increased with temperature but the contact angles decreased with temperature. Thus, despite zeta potential appears to have significant relation with contact angles, yet, it may not be considered as a primary driver of wettability and that further investigation is required to explore this effect.

The contact angle trends with temperature and salinity at ambient conditions were similar to those at high pressures and thus we hypothesized that zeta potential measurements at ambient conditions should follow similar trends at high pressure conditions. Furthermore, we conducted ATR-FTIR spectroscopy measurements on the coal substrates, and we measured an abundance of $\mathrm{OH}$ groups on the low rank coal, which is responsible for their hydrophilic nature, while high rank coals exhibited minimal $\mathrm{OH}$ peaks (and thus absence of $\mathrm{OH}$ groups), which explains their hydrophobic nature.

We furthermore provided implications of the measured data for $\mathrm{CO}_{2}$-storage and enhanced methane recovery and it can be concluded that high rank coal seams (at low temperature and high pressure) are most feasible for $\mathrm{CO}_{2}$-storage and enhanced methane recovery due to better

$583 \mathrm{CO}_{2}$-wettability and thus improved $\mathrm{CO}_{2}$-adsoprtion capacity.

\section{References}


2) Iglauer S, Paluszny A, Blunt MJ. . Simultaneous oil recovery and residual gas storage: A pore-level analysis using in situ X-ray micro-tomography. Fuel 2013;103:905-914.

3) Metz B, Davidson O, de Coninck H, Loos M, Meyer L. Intergovernmental panel on climate change special report on carbon dioxide capture and storage. Cambridge University Press; 2005.

4) Arif M, Al-Yaseri AZ., Barifcani A, Lebedev M, Iglauer S. Impact of pressure and temperature on $\mathrm{CO}_{2}$-brine-mica contact angles and $\mathrm{CO}_{2}$-brine interfacial tension: Implications for carbon geo-sequestration. J Colloid Interface Sci 2016a;462:208-215.

5) Arif M, Barifcani A, Lebedev M, Iglauer S. Structural trapping capacity of oil-wet caprock as a function of pressure, temperature and salinity. Int J Greenh Gas Con 2016b;50:112-120.

6) Hesse MA, Orr FM, Tchelepi HA. Gravity currents with residual trapping. J Fluid Mech 2008;611:35-60.

7) Iglauer S, Al-Yaseri AZ, Rezaee R, Lebedev M. $\mathrm{CO}_{2}$ wettability of caprocks: Implications for structural storage capacity and containment security. Geophys Res Lett 2015b;42:9279-9284.

8) Iglauer S, Paluszny A, Pentland CH, Blunt MJ. Residual CO2 imaged with X-ray microtomography. Geophys Res Lett 2011a;38:21.

9) Iglauer S, Wülling W, Pentland CH, Al-Mansoori SK, Blunt MJ. Capillary-trapping capacity of sandstones and sandpacks. SPE J 2011b;16:778-783.

10) Iglauer S. Dissolution trapping of carbon dioxide in reservoir formation brine-a carbon storage mechanism. In: Nakajima H, editor. Mass transfer - advanced aspects. Rijeka: InTech; 2011c. 
11) Gaus I. Role and impact of $\mathrm{CO}_{2}$-rock interactions during $\mathrm{CO}_{2}$ storage in sedimentary rocks. Int J Greenh Gas Con 2010;4:73-89.

12) Arif M, Barifcani A, Lebedev M, Iglauer S. $\mathrm{CO}_{2}$-wettability of low to high rank coal seams: Implications for carbon sequestration and enhanced methane recovery. Fuel 2016c;181:680-689.

13) Saghafi A, Javanmard $\mathrm{H}$, Pinetown K. Study of coal gas wettability for $\mathrm{CO}_{2}$ storage and $\mathrm{CH}_{4}$ recovery. Geofluids 2014;14:310-325.

14) Shojai Kaveh N, Rudolph ESJ, Wolf KHA, Ashrafizadeh SN. Wettability determination by contact angle measurements: hvBb coal-water system with injection of synthetic flue gas and $\mathrm{CO}_{2}$. J Colloid Interface Sci 2011;364:237-247.

15) Shojai Kaveh N, Wolf KH, Ashrafizadeh SN, Rudolph ESJ. Effect of coal petrology and pressure on wetting properties of wet coal for CO2 and flue gas storage. Int J Greenh Gas Con 2012;11:S91-S101.

16) Adamson AW, Gast, AP. The solid-liquid interface-contact angle. Phys Chem Surf 1997;4:333-361.

17) Iglauer $\mathrm{S}$, Pentland $\mathrm{CH}$, Busch $\mathrm{A}$. $\mathrm{CO}_{2}$ wettability of seal and reservoir rocks and the implications for carbon geo-sequestration. Water Resour Res 2015a;51:729-774.

18) Erbil HY. Solid and liquid interfaces. Oxford: Blackwell; 2006.

19) Alkan M, Demirbaş Ö, Doğan M. Electrokinetic properties of kaolinite in mono-and multivalent electrolyte solutions. Micropo Mesopor Mat 2005;83:51-59.

20) Buckley JS, Liu Y, Monsterleet S. Mechanisms of wetting alteration by crude oils. SPE J 1998;3:54-61. 
21) Nasralla RA, Nasr-El-Din HA. Double-layer expansion: is it a primary mechanism of improved oil recovery by low-salinity waterflooding?. SPE Reserv Eval Eng 2014;17:49-59.

22) Bustin RM, Barnes MA, Barnes WC. Diagenesis 10. Quantification and modelling of organic diagenesis. Geoscience Canada 1985;12.

23) Lander LM, Siewierski LM, Brittain WJ, Vogler EA. A systematic comparison of contact angle methods. Langmuir 1993;9:2237-2239.

24) Iglauer S, Salamah A, Sarmadivaleh M, Liu K, Phan C. Contamination of silica surfaces: Impact on water- $\mathrm{CO}_{2}-$ quartz and glass contact angle measurements. Int J Greenh Gas Con 2014;22:325-328.

25) Drelich J, Laskowski JS, Pawlik M, Veeramasuneni S. Preparation of a coal surface for contact angle measurements. J Adhes Sci Technol 1997;11:1399-1431.

26) Rodríguez K, Araujo M. Temperature and pressure effects on zeta potential values of reservoir minerals. J Colloid Interface Sci, 2006;300:788-794.

27) Laskowski J. Coal flotation and fine coal utilization. Vol. 14. Gulf Professional Publishing, 2001.

28) Akiya N, Savage PE. Roles of Water for Chemical Reactions in High-Temperature Water. Chem Rev 2002;102:2725-2750.

29) Ding LP. Investigation of bituminous coal hydrophobicity and its influence on flotation. Energy Fuels 2009;23:5536-5543.

30) Ramesh R, Somasundaran P. Chemical and wettability studies on coal, humic acid and cyclized humic acid. Fuel 1989;68:533-535.

31) Somasundaran P, Roberts CE, Ramesh R. Effects of oxidizing methods on the flotation of coal. Miner Eng 1991;4:43-48. 
32) Calemma V, Rausa R, Margarit R, Girardi E. FT-ir study of coal oxidation at low temperature. Fuel 1988;67:764-770.

691

33) Vinogradov J, Jackson MD. Zeta potential in intact natural sandstones at elevated temperatures. Geophys Res Lett 2015;42:6287-6294.

34) Butt HJ, Graf K, Kappl M. Physics and chemistry of interfaces. John Wiley \& Sons 2006.

697

41) Mugele F, Baret JC, (2005). Electrowetting: from basics to applications. Journal of

37) Ibrahim AF, Nasr-El-Din HA. Effects of Water Salinity, $\mathrm{CO}_{2}$ Solubility, and Gas Composition on Coal Wettability. In EUROPEC 2015. SPE 2015.

38) Fuerstenau DW, Rosenbaum JM, Laskowski J. Effect of surface functional groups on the flotation of coal. Colloid Surface, 1983;8:153-173.

39) Harvey PA, Nguyen AV, Evans GM. Influence of electrical double-layer interaction on coal flotation. J Colloid Interface Sci 2002;250:337-343.

40) Roshan H, Al-Yaseri AZ, Sarmadivaleh M, Iglauer S. On wettability of shale rocks. J Colloid Interface Sci 2016;475:104-111. Physics: Condensed Matter, 17(28), R705. 
42) Chi SM, Morsi BI, Klinzing GE, Chiang SH. Study of interfacial properties in the liquid carbon dioxide-water-coal system. Energy Fuels 1988;2:141-145.

43) Al-Yaseri AZ, Lebedev M, Barifcani A, Iglauer S. Receding and advancing $\left(\mathrm{CO}_{2}+\right.$ brine+ quartz) contact angles as a function of pressure, temperature, surface roughness, salt type and salinity. J Chem Thermodyn 2016;93:416-423.

44) Crawford RJ, Mainwaring DE. The influence of surfactant adsorption on the surface characterisation of Australian coals. Fuel 2001;80:313-320.

45) Abotsi GM, Bota KB, Saha G. Interfacial phenomena in coal impregnation with catalysts. Energy Fuels 1992;6:779-782.

46) Crawford RJ, Guy DW, Mainwaring DE. The influence of coal rank and mineral matter content on contact angle hysteresis. Fuel 1994;73:742-746.

47) Xu R, Hu B, He Q, Cai J, Pan Y, Shen J. Effect of compound inorganic nano-stabilizer on the stability of high concentration coal water mixtures. Fuel 2006;85:2524-2529.

48) Doymus K. The effect of ionic electrolytes and $\mathrm{pH}$ on the zeta potential of fine coal particles. Turk J Chem 2007;31:589-597.

49) Kaya, A., \& Yukselen, Y. (2005). Zeta potential of clay minerals and quartz contaminated by heavy metals. Can Geotech J, 42(5), 1280-1289.

50) Fuerstenau DW, Rosenbaum JM, You YS. Electrokinetic behavior of coal. Energy Fuels 1988;2:241-245.

51) Puri BR. Surface complexes on carbons. Chem Phys Carbon 1970;6:191-282.

52) Griffiths PR, De Haseth JA. Fourier transform infrared spectrometry. John Wiley \& Sons 2007;171. 
53) Socrates G. Infrared and Raman characteristic group frequencies: tables and charts. John Wiley \& Sons. 2004.

54) Manoj B, Kunjomana AG, Chandrasekharan KA. Chemical leaching of low rank coal and its characterization using SEM/EDAX and FTIR. J Min Mat Charact Eng 2009;8:821.

55) Tsai SC. Fundamentals of coal beneficiation and utilization. Elsevier Science \& Technology 1982;2.

56) Arif M, Barifcani A, Iglauer S. Solid/CO2 and solid/water interfacial tensions as a function of pressure, temperature, salinity and mineral type: Implications for CO2wettability and CO2 geo-storage, Int J Greenh Gas Con 2016;53:263.

57) Busch A, Gensterblum Y, Krooss BM. Methane and $\mathrm{CO}_{2}$ sorption and desorption measurements on dry Argonne premium coals: pure components and mixtures. Int J Coal Geol 2003;55:205-224.

58) Clarkson CR, Bustin RM. Binary gas adsorption/desorption isotherms: effect of moisture and coal composition upon carbon dioxide selectivity over methane. Int J Coal Geol 2000;42:241-271.

59) Mastalerz M, Gluskoter H, Rupp J. Carbon dioxide and methane sorption in high volatile bituminous coals from Indiana, USA. Int J Coal Geol 2004;60:43-55.

60) Reucroft PJ, Sethuraman AR. Effect of pressure on carbon dioxide induced coal swelling. Energy Fuels 1987;1:72-5. 